\title{
Football, Fan Violence, and Identity Fusion
}

Football violence has been a global problem for decades. A new way to approach the phenomenon comes from the theory of identity fusion, an extreme form of social bonding implicated in personally costly pro-group behaviours. Using British and Brazilian fan cultures to illustrate, this article discusses the ways in which identity fusion can help understandings of football violence. While hooliganism in the UK and the phenomenon of torcidas organizadas in Brazil operate under culturally distinct loci, the fundamental cognition underlying the extreme behaviours exhibited by both may be remarkably similar. Through this discussion, the football landscape is shown to offer researchers unique opportunities for understanding culture and the human psyche more broadly.

\section{Keywords}

Football violence; hooliganism; English football; Brazilian football; identity fusion; inter-group conflict; crowd management 
Football fandom is a well-established social phenomenon and many of its associated behaviours may be considered extreme, or indicative of high levels of group bonding and loyalty. For example, fans travel long distances, invest large amounts of money and time monitoring and participating in their teams' events and often display visual symbols of allegiance to their team, even lifelong and painful tattoos are not uncommon. Furthermore, the extent of inter-group conflict between rival fan groups is so commonplace that British football culture was once affectionately titled 'the English disease', while death rates from football-related violence continue to rise in Brazil (Murad, 2013; Raspaud and da Cunha Bastos, 2013). Fans are so heavily invested in football that match results have even been associated with circulatory disease death rates in men at both local and national levels (Kirkup and Merrick, 2003). This emotional, financial, and physical group commitment is particularly curious when football support is compared to other regional leisure or entertainment groups, such as the ballet or orchestras (Winegard and Deaner, 2010).

Football may lack an exegetic dimension and is not a self-conscious ritual but these points do not diminish the power of the ritual arena to forge social interaction and solidarity (Martyn and Taylor, 1997). Indeed, football matches constitute secular rituals by transcending the normal to create a liminal space within which males hug, kiss, and can enact a range of moods and emotions that are otherwise seen as emotional or irrational (Harvey and Piotrowska, 2013; Turner, 1969). The communitas generated by football crowd rituals allows for the formation of noncontractual relations that are not constrained by locality (Anderson, 1983). These 'neo-tribes' provide fans with shared, community derived experiences, which are potentially sought through a search for communitas (Maffesoli, 1996). Being enclosed together - be it a football ground, pub, or outdoor viewing space - in the knowledge 
of their team's and co-fans' shared history, participants are simultaneously bound in an appreciation for their side and against whatever confronts them (Maffesoli, 1996).

Here I use Brazilian and British football cultures to illustrate the utility of a cognitive approach to understanding fan violence. Despite historically middle-upper class roots in both Brazil and the UK, football has been coupled with the working classes for most of its lifetime. Nevertheless, football is a national sport for both nations, and the two are famed for a love of football. Each culture has a distinct cultural history and I have been fortunate enough to conduct fieldwork and run online studies in both. Football-related violence has been prominent in both cultures, albeit at different points in their histories. The two were therefore selected as very different societies with which to demonstrate a) the magnitude of football-related violence and b) how such differences can shape violence via a key cognitive factor developed in recent psychological research; identity fusion.

\section{Territory: Football Firms and Torcidas Organizadas}

Die-hard, violent supporter groups appear globally but are particularly fervent in certain contexts: most of Europe, particularly Italy, the UK and across Eastern Europe (Armstrong, 1998; Spaaij, 2006; Testa and Armstrong, 2010); some Australian cities (Knijnik, 2014); parts of Asia (e.g. Indonesia and Malaysia); parts of Africa, particularly the Arab world, e.g. Egypt (Tuastad, 2014); and Latin America (Brown, 2007; dos Reis et al., 2015). Brazilian and British football crowds are largely male; the masculinity of football matches, and related violence particularly, has been noted as key to how groups of fans construct themselves and interact (King, 1997a; 1997b). While one is traditionally machismo, the other is traditionally noted as being somewhat emotionally repressive - the former being ramped up by, the latter 
unleashed by, excessive match-day drinking. Organised fights between rival firms may have once been popular in the UK, but modern fan violence is largely spontaneous in the majority of contexts (Doidge and Lieser, 2017; King, 2002; Stott et al., 2007).

In the two present contexts, groups of alcohol-fuelled men with collectively combative outlooks are the steadfast at football matches, so it is perhaps little surprise that football fans have gained an international reputation as 'hooligans'. The use of cocaine, certainly in the UK, further emboldens these '(hyper-)masculine' identities among violent members of football gangs (Ayres and Treadwell, 2012). The bulk of the literature seems to avoid the complex, heterogeneous term 'hooligan', instead using terms like 'football-related violence' or 'football-related disorder'. Its etymological roots date to a century prior to this, in Britain, meaning 'gangs of rowdy youths' deriving from a notorious fighting London-Irish family name, 'Houlihan' (Pearson, 1983 in Dunning, 2000). It may refer to violence, arson, taunting songs, the intention to fight, or a desire to be publically associated with groups with a reputation for violence. Though it is true that football fans clearly fall on a spectrum, from mild spectators to die-hard supporters, football violence is a global and persistent problem, spanning at least three continents and five decades.

In Brazil deaths from football-related violence have been steadily increasing ${ }^{1}$. The costs to government spending on security are also significant. The UK, which is noted for decreasing the culture of football hooliganism after decades of violence and international bans, still spends over $£ 7.5 \mathrm{~m}$ on policing football matches each year (Bridge, 2008). This is a figure representing just a fraction of the nation's highest performing league. For the sake of comparison, in Italy, a nation known for 'ultras', 
about $€ 40 \mathrm{~m}$ were spent annually on law enforcement officers for football matches in the 1990s (De Biasi, 1997).

Football-related group violence is particularly prominent in Brazil, a country with one of the highest homicide rates in the world (Steeves et al., 2015). For instance, in Brazil, more people died as a result of fire-arm homicides than the combined total of the 12 biggest armed conflicts in the entire world during the same period, and two of every five Brazilian male aged 15-24 die as the result of a homicide. As such, football-related violence is an acute threat to football fans in Brazil. Not only does conflict within football take place against a backdrop of violent inter-group clashes and gang violence, but deaths relating to football-conflicts specifically have escalated in recent years: from 14 deaths 1999-2003 (a four year period) to 14 deaths in just a year 2007-2008 (Murad, 2013; Raspaud and da Cunha Bastos, 2013). As a result, Brazilian law dictates that in some cities opposing fans cannot be seated together or even attend matches. Physical barriers alleviate some of the football-violence tragedies, but they do not tackle the underlying mechanisms that prompt such wide-scale conflict.

In the early 1990s the UK's football hooliganism problem was internationally recognised and reached crisis point, leading to widespread crowd management interventions by both stadia and police. The legacy of Britain's football violence endures, forming a congruent part of pop-culture although the threat of physical violence, far less actual death, has greatly diminished. Brazilian 'hooligan' (or torcida organizada) culture took off in the 1980s, just as British football violence was reaching its pinnacle, and remains a prominent feature of the football landscape (Lopes, 2013). Torcidas organizadas translates as 'organised fans' and refers to fans that are members of organised fan or supporter groups. These groups have a bad 
reputation for anti-social behaviour and violence. Violence among these groups is often also internal, leading to a greater risk of fighting within stadia - though Brazilian football matches are generally safe to attend. Torcidas organizadas may also be related to territorial gangs. As cynical as one may be about corruption within football in the UK, it is recognised as a much more salient feature of Brazilian football with torcidas organizadas being subsidised by clubs (e.g. tickets exchanged for intimidation of opponent fan groups or political opponents).

\section{Perspectives on Fan Violence}

Traditionally, sociological work suggests that violence within hooligan cultures is actually more asserted by outsiders and is a construct propagated by the media and politicians, rather than being a social scientific or social psychological concept (Dunning et al., 1986). Though external factors may have an impact, the behaviours associated with 'hooligan' cultures, as they are commonly known, are largely accepted to stem from a British, working class variant in the 1960s. According to Dunning, what actually distinguishes this subset of 'hard-core fans' is not just involvement in an organised, violent group, but greater dedication to their team and fellow fans, including more match attendance and a potentiality for low-level violence.

In contrast to Dunning's presentation of football hooliganism being a universal phenomenon, Spaaij asserts that hooliganism, as a 'new' form of collective violence (unlike general violence), is specifically European, Latin American and somewhat Australian in nature (Spaaij, 2006). He proposes the following definition of, which appears to hold true exclusively in the cultural contexts listed above: '[hooliganism is] the competitive violence of socially organized fan groups in football, principally directed against opposing fan groups' (p 18). 
There is sociological and anthropological evidence to suggest that at least some football-related disorder is ritualised, and pertains more to the performance of status and aggression, than actual conflict or violence. For instance, though football deaths do occur, there tend to be minimal injuries in confrontations due to organised, rule-led conflict (Marsh and Harré, 1978). Potter \& Wetherell suggest that submissive behaviours allow hostilities to end whilst maintaining both personal and group honour through ritualised chases Potter, 1987 \#206. From an evolutionary perspective, this kind of intra-sex conflict strategy is perhaps reminiscent of ritualised displays in other species, e.g. rutting in stags. Potter \& Wetherell argue that fans know that the behaviour is unlikely to be truly dangerous, rather it reproduces media exaggerations and maintains hooligan cultures as an exciting, yet safe, domain, which the authors describe as a functional rhetoric. This may explain the behaviour of some 'risk supporters', but does not explain its origins or why individuals actually find the behaviour exciting or engaging in the first place.

Developing Potter \& Wetherell's argument about the media's role in the proliferation of football-related violence, there's also the view from both Redhead and Armstrong that hooligan culture, rather than posing a societal threat, is really a reflection of mass media hysteria and a moral panic \{Armstrong, 1998 \#351;Redhead, $2008 \# 505\}$. However, football - once the English disease - is now more like 'a cold sore', flaring up every so often and the moral panic account was established before many modern supporters were even born (Ingle, 2013).

Marxist and class accounts for British hooligan culture are now widely rejected (Dunning, 2000; Taylor, 1971; Taylor, 1987). Instead, two related explanations tend to be favoured: first, the idea that football-related violence has a negative impact on club finances, leading both clubs and fans to reduce such 
behaviours (Jewell et al., 2014). With the economic transformation of European football toward the end of the last century, clubs have gained increased political control of the game and, arguably, their fans (though there are clear exceptions, e.g. Borussia Dortmund, Germany) (King, 2002; King, 2003). Second, the welldocumented correlation between improved stadia management and decreased reported disorder \{Cleland, 2015 \#418). Stadia management techniques include seated stadia, the use of turnstiles, more CCTV, and guards (but not necessarily police) lining the pitch. However, the core elements of football hooliganism, and specifically intergroup violence, still exist on the global stage. The next section considers current manifestations of extreme fan cultures in the UK and Brazil, paying special attention to violent outcomes.

\section{Prosocial Cognition?}

It seems unlikely that the fans engaged in these violent behaviours are engaging in a safe 'functional rhetoric', to return to Potter \& Wetherell. Although the observations derived from sociological and anthropological research may be informative, few address the psychological underpinnings of extreme fan violence or of inter-group conflict. There are, in fact, many global examples of football fans engaging in prosocial activities. In the UK, for instance, many volunteers who have worked on the UK Premier League club Everton's community branch since austerity measures were introduced to the community in 2010 (Parnell et al., 2015). Furthermore, British fans have been found to attack Islamaphobic comments when a Muslim player joins one's team (Middlesbrough) compared to defending Islamaphobic comments when one's fan base has been making Islamaphobic chants (Newcastle) (Millward, 2008). In Brazil, youth fan groups (torcidas joven) holding demonstrations and protests in 
Brazil (de Hollanda and da Camara Teixeira, 2017). To what extent could the cognition underlying fan violence be considered to have roots in prosociality?

Holistic theories of football-related violence certainly ought to address the cognition underlying inter-group violence which, being group based, will necessarily have a social element. Work on micro-sociological and social psychological group processes has started to address this issue: be it considerable work on the Elaborated Social Identity Model (ESIM) of Crowd Behaviour (Stott et al., 2007; Stott et al., 2001); micro-analysis of social interaction and confrontation (Collins, 2009); or an emphasis placed on interactions and external factors involving fans, fan groups, and police (King, 2003), though King's recent work on social cohesion in the military may also be relevant to fusion approaches to football violence (King, 2015). An example of best practice integrating interaction-based approaches with microsociological techniques comes from research by Doidge and colleagues (Doidge, 2013; Doidge and Lieser, 2017).

The ESIM is particularly relevant here because it, like identity fusion, is rooted in social identity theory. The ESIM has already been used to good effect to understand the presence and absence of football violence. Specifically, the model proposes that the 'norms' of hooligan behaviour are an outcome of participants' shared social identity (Stott et al., 2008). As such, the model focuses on police force in constructing 'hooligan' social identities, perceived legitimacy around violence, and 'self-regulation' among fan groups. The ESIM has strengths in explaining how situational focuses contribute to hooliganism, e.g. group membership results in shared norms around violence, but there are weaknesses when it comes to explaining individual differences. For instance, why are some members of extreme fan groups more violent than others? 
Fusion theory complements the extant literature by helping to address this gap in the literature. A new body of research suggests that for some fans, football generates a sense of belonging that connects self with others, and group with stadium or territory (Newson et al., Under review; Newson et al., Accepted). This visceral 'oneness' with the group leads to extraordinary pro-group behaviours, the most renowned of which is football violence, but which can also manifest in non-violent altruism (e.g. charitable work), which is discussed toward the end of this article. To investigate, this article employs a critical literature review on fusion theory and uses contrasting British and Brazilian examples to connect the theory to the issue of fan violence.

\section{Identity Fusion}

Fusion theory describes a particularly intense form of group bonding whereby the boundary between personal and group identities becomes porous, i.e. the personal and social selves become fused (Swann and Buhrmester, 2015). For persons who report being strongly fused to a group, group activities are intensely personal, leading to increased feelings of agency, invulnerability, and kinship, in group contexts (Swann et al., 2012). This is in contrast to the hydraulic nature of identification where either the personal or the social self is activated (Gómez et al., 2011; Tajfel and Turner, 1979). As a result, highly fused individuals are particularly likely to put their lives at risk to save ingroup members when threatened (Swann et al., 2014a; Swann et al., 2014b; Swann et al., 2010a) and provide financial and socio-emotional support to needy ingroup members (Buhrmester et al., 2015; Swann et al., 2010b). Research in the Middle East has found that highly fused individuals are more likely to engage in combat on behalf of or in the name of the group (Sheikh et al., 2016; Whitehouse et al., 2014). Fusion theory would suggest that fans who are happy to wear a team shirt, 
sing team chants and watch games are experiencing a different psychological phenomenon in relation to those fans who in addition to such behaviours, engage with feelings of deep personal investment, self-sacrificial behaviour and extreme pro-group endorsement. This latter group of fans will 'go down with the ship' and be more resilient to negative team outcomes (Newson et al., 2016). Influenced by Durkheim, King considers 1990s British 'lad' fandom as a form of group love; team worship is thus 'a symbol of the values and friendship which exist between the lads' (King, 1997a) (p. 333). Understanding this deep and often enduring connection between fans is precisely what fusion theory may be able to contribute toward. Indeed, the basis for fusion has already been likened to mechanical solidarity.

As to why some fans (or indeed some individuals outside of football) become more fused to their groups than others, the question remains open. Whitehouse and colleague's dysphoric pathway to fusion indicates that sharing particularly traumatic events as a group can help fuse group and personal identities (Jong et al., 2015; Newson et al., 2016; Whitehouse et al., 2017). However, questions remain as to which individuals experience such events as more or less personally defining.

Fusion research stems from social psychology and typically employs wellvalidated survey measures (i.e. verbal, pictorial and digital scales to measure fusion) (Gómez et al., 2011; Jimenez et al., 2016; Swann et al., 2009). Experiments have been conducted online, in laboratories, and in the field to assess the causes and consequences of fusion. For instance, in (Whitehouse et al., 2017) both football fans and martial arts practitioners completed a number of online measures which demonstrated associations between suffering (team defeat and painful initiations respectively) and higher fusion levels, and between fusion and self-sacrificial behaviour (e.g. in the hypothetical trolley dilemma scenario, in which participants 
choose whether they would rather sacrifice themselves to save imperilled group members or let the other group members die). In addition, qualitative interviews are also used in conjunction with the quantitative methodologies, which are then analysed for relevant features. In the field, pictorial measures or reduced verbal scales have been used. For instance pictorial scales have been used with Libyan revolutionaries (Whitehouse and Lanman, 2014) where translation and literacy could have been problematic; and reduced verbal scales have been used in the field during live World Cup matches in Brazil where many participants have had to be quickly accessed (Newson et al., Accepted).

Sports fandom, particularly football, is an especially relevant context to investigate the relationship between fusion and extreme pro-group behaviours, such as physical violence because: (a) it appears globally; (b) there is substantial variation in behaviour among fans, e.g. between so called 'scarfers' and 'hooligans'; (c) it extends previous research on the relationship between identification and outgroup hostility in sports fans (Donahue and Wann, 2009; Wann et al., 1999) and; (d) it extends previous fusion research on military, paramilitary, and radical groups (Buhrmester and Swann, 2015).

If violence among extreme fans is driven by fusion, we would expect it to be discriminatory and triggered by the presence of a group threat, i.e. fusion-driven violence will be targeted at specific outgroups (e.g. rival fans) (Fredman et al., 2017). Indeed, recent research has shown that for fused Brazilian torcidas organizadas, violence is directed specifically toward rival fans rather than general fans or the police (Newson et al., Under review). These fans reported significantly more physical violence toward rival fans than they did to the other categories, while for non-torcida organizada members and those who scored low for fusion there were no statistical 
differences in the amount of violence they reported between any of the groups. Outgroups are made continually salient for football fans and particularly members of extreme fan organisations. This is because if the group is threatened, due to the merging of personal and social selves, the individual perceives this as an attack on both group and self, and is likely to engage in a hostile stance.

The cognition underlying this propensity for extreme social bonding has been found in at least eleven countries across six continents and is therefore likely be found in any football fan culture (Swann et al., 2014a). Precisely how that extreme group alignment is expressed behaviourally will be shaped and mediated by any number of socio-cultural factors, including social mobility and structural inequalities, political systems, national approaches to gender identities and sexuality, attitudes toward conservatism and liberalism, and cultural tightness and looseness. Nonetheless, this devotion to one's group and the extreme behavioural outcomes that tend to be associated with it can be seen in any number of other tight-knit groups across time and space. Football therefore provides a relatively safe, international platform from which to investigate extreme group bonding and hostile behaviours that could impact our understanding of intergroup conflict more broadly. Fusion explains individual differences and may thus be useful for comparing cultures, though not necessarily explaining societal differences. This article does not propose to replace, but rather to complement, existing explanations of structural inequalities, political systems, and national approaches to gender identities, sexuality, and class that currently explain extreme fandom.

\section{Implications}

If football-related violence is driven by an extreme pro-group mentality could it be harnessed for more socially desirable outcomes? Within football culture, some fans 
already recognise this potential. For instance, according to a substantial number of British football fans can be described as 'hoolifans' - a term used to describe fans who support members of their team's extreme fan groups and risk supporters (i.e. those at risk of engaging in violent behaviours) (Rookwood and Pearson, 2012). In addition, some fans that were generally critical of football-related disorder or 'hooliganism' were found to laud such behaviours under certain cultural circumstances. These included derby days or after a perceived miscarriage of justice, i.e. when the group's needs out-rank their individual needs. Perhaps risk supporters, if they are more highly fused, also experience group needs more urgently, resulting in more extreme behaviours.

The personally costly behaviours associated with fusion are not necessarily negative. One non-violent way of displaying group commitment in football is regularly attending away matches- sometimes travelling long distances, even half way around the world, to support one's club at great personal cost. For example, around 30,000 Corinthians fans from Brazil travelled halfway across the world to support their league-level club in the FIFA Club World Cup - fans quit their jobs, sold their cars, and even their fridges to attend the match (Goddard and Sloane, 2014; Montague, 2012). Although fusion theory may predict that the most costly behaviours (e.g. away match attendance) are demonstrated by fused fans, that is not to say that away match attendees will necessarily be more violent (although it may be expected when outgroup threat is increased). As football matches tend to be largely attended by home supporters (particularly when there is a greater distance to cover), these matches can be particularly intense for the away supporters, as well as financially costly and taking up considerable time (even within a relatively small country like the UK dedicated fans will often get up before sunrise to get on coaches to attend away 
matches on the other side of the country). As well as being an expression of loyalty, away match attendance incurs measurable benefits for the team, as team's chances have been found to improve via increased crowd noise and influencing referee decisions (Nevill et al., 2002).

In what other ways could the extreme behaviours associated with fusion be harnessed for social good, to benefit other fans, or even bigger, extended communities? Recent research has shown that while it is challenging to de-fuse individuals, pro-group sentiments can be extended to wider groups. For instance, the notion of 'protection' granted by risk supporters could be stretched to encompass the wider community through exercises that encourage participants to recognise the transformative experiences they have shared with broader fan groups (Newson et al., 2016; Whitehouse et al., 2017). In this way fusion has the potential to generate progroup behaviours that are more socially acceptable, e.g. charity work. In the UK, we might find highly fused fans setting up food banks for other needy fans during economic recessions. In Brazil, highly fused Chapecoense fans may have travelled to the site where their team's plane crashed (and the squad wiped out) in 2016, laying wreaths or writing letters to affected fans or players' families. The highly choreographed displays that torcidas organizadas are renowned for could also be investigated and potentially harnessed to extend the ingroup altruism we observed in the present sample to generalised prosociality, or even prosociality towards outgroup members (Reddish et al., 2016).

Cognitive understandings of the mechanisms underlying fan violence could also help reduce violence by re-framing police tactics. Though fan violence may not be primarily directed toward the police, the ways in which police manage football crowds can have a deep impact on the ways in which fans behave. First and 
unsurprisingly, brutal police tactics may serve to increase hostility toward the police by increasing perceived threat levels toward the ingroup, thus making them more likely to be a target for violence. Second, extreme police tactics such as kettling, the use of tear gas or deployment of military personal to intervene in fan activities may create enduring, 'self-transform' experiences that only further fuse the individual to the group (Newson et al., 2016; Whitehouse et al., 2017). Instead, the power of selftransformative experiences to forge group identities to reduce inter-group fighting could be investigated by asking participants to reflect on experiences shared by the broader group, i.e. football fans or the nation, and encouraging fusion with extended groups, potentially even encompassing their traditional rivals.

There is substantial variation in police practice according to region in both Brazil and the UK. However, overall, police presence at live matches in the UK has decreased in recent decades (with the exception of derby matches). In their place are more club-selected stewards, who appear to have a more positive impact on fans and the reduction of fan violence; potentially by reducing the appearance of threat levels meaning that highly fused fans are not on as high an 'alert' for hostility. In Brazil, police brutality tends to be greater issue. Whether the brutality causes the violence, or the brutality is in response to the violence is an on-going debate. In recent years, schemes have been piloted where mothers act as stewards at football matches, e.g. Sport Club do Recife trained up 'Seguranca Mae' (Security Mums). This reflects female engagement in football in Brazil and a cultural regard for mother figures (related in part to the Cult of the Virgin Mary in Catholicism). Placing mothers on the pitch perhaps primes fans for fusion to their families during the match, which may help reduce the extremity of fusion-to-football associated behaviours during games. 
Such a system may not work so well in the UK, where mothers do not have quite the same symbolic as they do in Brazil.

\section{Conclusions}

The concept of 'us' and 'them' cannot be avoided in competitive sport, but the territorial element of football, coupled with drinking cultures, makes football-related violence a recurrent international issue. Though this has subsided, or perhaps become better concealed in the UK, threats from football-related violence are acute in Brazil. The reasons for such differences are complex: first there is the issue of cultural norms around violence and culturally acceptable outlets for such violence. Second, masculinity appears to be key to the emergence of violent identities, as noted in much literature on football violence, but also with far-reaching studies incorporating neurobiology, group dynamics and fusion to analyse terrorist behavior (MöllerLeimkühler, 2017). Variation in such factors and, thirdly, the environment (e.g. stadia construction, use of CCTV etc.) likely help shape fusion outcomes considerably. These areas can help us understand why the expression of extreme fandom has cultural similarities (e.g. largely male) and differences (e.g. increasing violence in Brazil and decreasing violence in the UK).

With extreme social bonding plausibly intensifying under such conditions, we as researchers have a unique opportunity to (a) study intergroup conflict internationally and (b) conduct cross-cultural work within the same parameters, i.e. within the context of football fandom. This finely balanced comparative work could only realistically be matched on such a scale by research on followers of international religions. Cross-culturally analysing who fans are informs us not only of their immediate football cultures, but provides both a comparative structure from which to understand the broader cultures within which they are situated, and offers us insights 
into the workings of the human psyche. Although caution should be applied when generalising psychological studies to new populations, identity fusion and closely related theories offer an opportunity for us to better understand the deeply pro-social cognition underlying the behaviour of some highly fused football fans and enact positive social change.

\section{Acknowledgements}

Thank you to Professor Harvey Whitehouse, Dr Michael Buhrmester and Sophie Bateman for your help in the formation of ideas and insightful comments on earlier drafts.

\section{Funding}

This work was supported by the Economic and Social Research Council [ES/J500112/1; RES-060-25-467 0085] and an Advanced Grant from the European Research Council (ERC) under the European Union's Horizon 2020 Research and Innovation Programme (grant agreement No. 694986).

\section{Notes}

1. 14 deaths $1999-2003,14$ deaths $2004-06,14$ deaths 2007-08, 21 deaths 2009-10, and 34 deaths 2011-12.

\section{References}

Anderson B (1983) Imagined Communities: Reflections on the Origin and Spread of Nationalism. London: Verso.

Armstrong G (1998) Football hooligans: knowing the score. Berg Publisher Ltd. Ayres TC and Treadwell J (2012) Bars, drugs and football thugs: Alcohol, cocaine use and violence in the night time economy among English football firms. Criminology \& Criminal Justice 12: 83-100.

Bridge R (2008) Premier League Policing Costs 2007/8. In: police' Fspf (ed) Police forces (FOI requests). http://news.bbc.co.uk/1/hi/uk/7553875.stm.

Brown S (2007) Football fans around the world: From supporters to fanatics. Routledge. 
Buhrmester MD, Fraser WT, Lanman JA, et al. (2015) When terror hits home: Identity fused Americans who saw Boston bombing victims as "family" provided aid. Self and Identity 14: 253-270.

Buhrmester MD and Swann WB (2015) Identity Fusion. Emerging Trends in the Social and Behavioral Sciences: An Interdisciplinary, Searchable, and Linkable Resource.

Collins R (2009) Violence: A micro-sociological theory. Greenwood Publishing Group.

De Biasi R (1997) The policing of mass demonstrations in contemporary democracies, the policy of hooliganism in Italy. EUI Working Papers.

de Hollanda BB and da Camara Teixeira R (2017) Brazil's organised football supporter clubs and the construction of their public arenas through FTORJ and ANATORG. Football Fans, Rivalry and Cooperation: 76.

Doidge M (2013) 'The birthplace of Italian communism': political identity and action amongst Livorno fans. Soccer \& Society 14: 246-261.

Doidge M and Lieser M (2017) The importance of research on the ultras: introduction. Sport in Society: 1-8.

Donahue T and Wann DL (2009) Perceptions of the Appropriateness of Sport Fan Physical and Verbal Aggression: Potential Influences of Team Identification and Fan Dysfunction. North American Journal of Psychology 11.

dos Reis H, Lopes F and Martins M (2015) Eric Dunning's explanations about hooliganism in the Brazilian context: a critical review. Movimento 21: 617632.

Dunning E (2000) Towards a sociological understanding of football hooliganism as a world phenomenon. European Journal on Criminal Policy and Research 8: 141-162.

Dunning E, Murphy P and Williams J (1986) Spectator Violence at Football Matches: Towards a Sociological Explanation. The British Journal of Sociology 37: 221-244.

Fredman LA, Bastian B and Swann Jr WB (2017) God or Country? Fusion With Judaism Predicts Desire for Retaliation Following Palestinian Stabbing Intifada. Social Psychological and Personality Science: 1948550617693059.

Goddard J and Sloane P (2014) Handbook on the Economics of Professional Football. Edward Elgar Publishing.

Gómez Á, Brooks ML, Buhrmester MD, et al. (2011) On the nature of identity fusion: Insights into the construct and a new measure. Journal of Personality and Social Psychology 100: 918-933.

Harvey A and Piotrowska A (2013) Intolerance and joy, violence and love among male football fans: towards a psychosocial explanation of 'excessive' behaviours. Sport in Society 16: 1404-1413.

Ingle S (2013) Football hooliganism, once the English disease, is more like a cold sore now. The Guardian.

Jewell RT, Simmons R and Szymanski S (2014) Bad for business? The effects of hooliganism on English professional football clubs. Journal of Sports Economics 15: 429-450. 
Jimenez J, Gomez A, Buhrmester MD, et al. (2016) The Dynamic Identity Fusion Index A New Continuous Measure of Identity Fusion for Web-Based Questionnaires. Social Science Computer Review 34: 215-228.

Jong J, Whitehouse H, Kavanagh C, et al. (2015) Shared Negative Experiences Lead to Identity Fusion via Personal Reflection. PLoS ONE 10.

King A (1997a) The lads: Masculinity and the new consumption of football. Sociology 31: 329-346.

King A (1997b) The postmodernity of football hooliganism. British Journal of Sociology: 576-593.

King A (2002) End of the terraces: The transformation of English football. Bloomsbury Publishing.

King A (2003) The European ritual: Football in the new Europe. Ashgate Publishing, Ltd.

King A (2015) Frontline: Combat and Cohesion in the twenty-first century. OUP Oxford.

Kirkup W and Merrick DW (2003) A matter of life and death: population mortality and football results. Journal of Epidemiology and Community Health 57: 429-432.

Knijnik JD (2014) New culture in the making: an ethnographic study of the Western Sydney Wanderers Football Club fandom culture. Contemporary Ethnography Across the Disciplines (CEAD 2014): Sensual Landscapes of Ethnography, 26-28 November 2014, University of Waikato, Hamilton, Aotearoa, NZ: 72.

Lopes FTP (2013) Dimensões ideológicas do debate público acerca da violência no futebol brasileiro. Revista Brasileira de Educação Física e Esporte 27: 597-612.

Maffesoli M (1996) The contemplation of the world: Figures of community style. U of Minnesota Press.

Marsh P and Harré R (1978) World of Football Hooligans. Human Nature 1: 6269.

Martyn P and Taylor R (1997) Something for the weekend, sir? Leisure, ecstasy and identity in football and contemporary religion. Leisure Studies 16: 3749.

Millward P (2008) Rivalries and Racisms:'Closed'and'Open'Islamophobic Dispositions Amongst Football Supporters. Sociological Research Online 13: 5.

Möller-Leimkühler AM (2017) Why is terrorism a man's business? CNS spectrums: $1-10$.

Montague J (2012) Corinthians: Craziest fans in the world? Available at: http://edition.cnn.com/2012/12/14/sport/football/football-club-worldcup-crazy-fans-corinthians/.

Murad M (2013) Práticas de violência e mortes de torcedores no futebol brasileiro. Revista USP: 139-152.

Nevill AM, Balmer NJ and Mark Williams A (2002) The influence of crowd noise and experience upon refereeing decisions in football. Psychology of Sport and Exercise 3: 261-272.

Newson M, Bortolini T, Buhrmester M, et al. (Under review) Brazil's Football Soldiers: Social bonding and inter-group violence Evolution and Human Behavior. 
Newson M, Buhrmester M, Hattori WT, et al. (Accepted) Attack and Defend: international out-group hostility, pro-group biases, and physiological arousal in World Cup football. Self and Identity.

Newson M, Buhrmester M and Whitehouse H (2016) Explaining Lifelong Loyalty: The Role of Identity Fusion and Self-Shaping Group Events. PLoS ONE 11: e0160427.

Parnell D, Millward P and Spracklen K (2015) Sport and austerity in the UK: An insight into Liverpool 2014. Journal of Policy Research in Tourism, Leisure and Events 7: 200-203.

Raspaud M and da Cunha Bastos F (2013) Torcedores de futebol: violence and public policies in Brazil before the 2014 FIFA World Cup. Sport in Society 16: 192-204.

Reddish P, Tong EM, Jong J, et al. (2016) Collective synchrony increases prosociality towards non - performers and outgroup members. British Journal of Social Psychology.

Rookwood J and Pearson G (2012) The hoolifan: Positive fan attitudes to football 'hooliganism'. International Review for the Sociology of Sport 47: 149-164.

Sheikh H, Gómez Á and Atran S (2016) Empirical evidence for the devoted actor model. Current Anthropology 57: S000-S000.

Spaaij R (2006) Understanding football hooliganism: a comparison of six Western European football clubs. Amsterdam University Press.

Steeves GM, Petterini FC and Moura GV (2015) The interiorization of Brazilian violence, policing, and economic growth. EconomiA 16: 359-375.

Stott C, Adang O, Livingstone A, et al. (2007) Variability in the collective behaviour of England fans at Euro2004:'Hooliganism', public order policing and social change. European Journal of Social Psychology 37: 75100.

Stott C, Adang O, Livingstone A, et al. (2008) Tackling football hooliganism: A quantitative study of public order, policing and crowd psychology. Psychology, Public Policy, and Law 14: 115.

Stott C, Hutchison P and Drury J (2001) 'Hooligans' abroad? Inter-group dynamics, social identity and participation in collective 'disorder' at the 1998 World Cup Finals. British Journal of Social Psychology 40: 359-384.

Swann WB and Buhrmester MD (2015) Identity Fusion. Current Directions in Psychological Science 24: 52-57.

Swann WB, Buhrmester MD, Gómez A, et al. (2014a) What makes a group worth dying for? Identity fusion fosters perception of familial ties, promoting self-sacrifice. Journal of Personality and Social Psychology 106: 912.

Swann WB, Gómez Á, Buhrmester MD, et al. (2014b) Contemplating the ultimate sacrifice: Identity fusion channels pro-group affect, cognition, and moral decision making. Journal of Personality and Social Psychology 106: 713.

Swann WB, Gómez Á, Dovidio JF, et al. (2010a) Dying and Killing for One's Group: Identity Fusion Moderates Responses to Intergroup Versions of the Trolley Problem. Psychological Science 21: 1176-1183.

Swann WB, Gómez Á, Huici C, et al. (2010b) Identity fusion and self-sacrifice: Arousal as a catalyst of pro-group fighting, dying, and helping behavior. Journal of Personality and Social Psychology 99: 824-841. 
Swann WB, Gómez Á, Seyle DC, et al. (2009) Identity fusion: The interplay of personal and social identities in extreme group behavior. Journal of Personality and Social Psychology 96: 995-1011.

Swann WB, Jetten J, Gómez Á, et al. (2012) When group membership gets personal: A theory of identity fusion. Psychological Review 119: 441-456.

Tajfel $\mathrm{H}$ and Turner JC (1979) An integrative theory of intergroup conflict. The social psychology of intergroup relations 33: 47.

Taylor I (1971) Football mad: a speculative sociology of football hooliganism. The sociology of sport 4: 357-377.

Taylor I (1987) Putting the Boot Into a Working-Class Sport: British Soccer After Bradford and Brussels. Sociology of Sport Journal 4.

Testa A and Armstrong G (2010) Football, fascism and fandom: The ultras of Italian football. A\&C Black.

Tuastad D (2014) From football riot to revolution. The political role of football in the Arab world. Soccer \& Society 15: 376-388.

Turner V (1969) Liminality and communitas. The ritual process: Structure and anti-structure: 94-130.

Wann DL, Carlson JD and Schrader MP (1999) The impact of team identification on the hostile and instrumental verbal aggression of sport spectators. Journal of Social Behavior \& Personality.

Whitehouse H, Jong J, Buhrmester M, et al. (2017) The evolution of extreme cooperation via shared dysphoric experiences. Nature: Scientfic reports.

Whitehouse H and Lanman JA (2014) The Ties That Bind Us: Ritual, fusion, and identification. Current Anthropology 55: 674-695.

Whitehouse H, McQuinn B, Buhrmester M, et al. (2014) Brothers in arms: Libyan revolutionaries bond like family. Proceedings of the National Academy of Sciences 111: 17783-17785.

Winegard B and Deaner RO (2010) The evolutionary significance of Red Sox nation: sport fandom as a by-product of coalitional psychology. Evol Psychol 8: 432-446. 